\title{
From the bench to the field: control of parasitic infections within primary health care
}

\author{
M. TANNER
}

Swiss Tropical Institute, Department of Public Health and Epidemiology, 4002 Basel, Switzerland

\begin{abstract}
SUMMARY
During the last decade there has been a great increase in the number of countries that have endorsed the primary health care (PHC) policy at national level, set up national guidelines for it and launched its large-scale implementation. In addition, there have been many important developments with regard to appropriate, cost-effective technologies, training concepts and approaches to securing community participation. These achievements have produced numerous encouraging results. However, although the control of parasitic infections integrated into PHC systems has often been initially successful, these achievements could often not be sustained. Using case studies, mainly concerning schistosomiasis, as examples, control technologies and their applicability within PHC are discussed at three levels; the identification of public health priorities, the community-based implementation of control and the process of evaluation and monitoring. There is a great potential for the integration of a substantial part of control activities, particularly morbidity control, into PHC, provided that the aims and sequences of control activities are well matched with the felt needs of the communities concerned. This implies that the biomedical researcher, the epidemiologist and the health planner need to consider the indigenous health perspectives of the affected community. For example, recent progress in the laboratory in the development of vaccines against parasites needs to be complemented by field studies that continuously validate, standardize and assess the applicability of the proposed measures. This kind of interplay will form the basis for participatory approaches in health planning and make it possible for control activities to be integrated into existing PHC structures and to respond to the needs of the communities concerned.
\end{abstract}

Key words: health care, schistosomiasis, cost-effective control, field parasitology.

\section{IN TRODUCTION}

During the last decade of Primary Health Care (PHC) implementation, discussion has been dominated on the one hand by managerial and policy issues and approaches to strengthening national capacity building. This has resulted in a gradual increase of countries that have endorsed the PHC policy at national level, set up national guidelines and launched its large-scale implementation (WHO, 1982). On the other hand, in-depth research efforts through north-south or south-south collaboration have helped to establish epidemiological data for many socio-ecological settings and promoted costeffective strategies for disease control, often initiated by multilateral organizations such as WHO and UNICEF.

Based on wide-ranging and sound political support, national will and public efforts, control strategies and programmes were launched and produced numerous encouraging results, reflected in many small- and large-scale success stories (partly summarized by Morley, Rohde \& Williams, 1983; Heggenhougen, 1984; Walsh \& Warren, 1986). The list of successes also includes major advances in the control of parasitic disease. However, most of these disease control efforts and programmes, though initially promising, could not sustain the levels of control achieved during the attack phase. Several reasons may account for this failure. (1) There were only limited attempts to integrate these disease control activities into existing health services; i.e. most of the parasitic disease control operations were run as parallel activities to the existing health care delivery structures. (2) The programmes often did not include appropriate mechanisms to ensure evaluation and monitoring during the maintenance phase. (3) The technologies applied-although meeting criteria such as being simple and costeffective-did not match the cultural and social features of the communities in which they were applied. (4) Many of the technologies developed and shown to be effective in the laboratory, had not been fully validated for their efficacy, effectiveness and efficiency in the field.

It is far beyond the scope of this paper to review comprehensively $\mathrm{PHC}$ principles and their implementation or to summarize all the recent advances in laboratory and field parasitology. Using case studies, mainly concerning schistosomiasis, the following account illustrates how laboratory findings can be better translated into control action in the endemic areas and how these attempts might reach sustainability by their integration into the existing health care delivery services, particularly into PHC. 


\section{CONCEPTS}

The step from the laboratory bench to the field is often understood as a one-way process that provides a technology developed in a laboratory ready for application in the field. It may also be seen as an interaction between the basic or applied laboratorybased research and the epidemiological, operational or health systems research. However, if our efforts in the laboratory - even those based on field validation of new technologies - aim at solving both community health problems and at improving the general health status and the living standard of communities, our view of the move from the bench to the field should include not only the concepts of laboratory science but also those of clinical and community medicine in a given country, i.e. we must take into account the social and political anatomy of an endemic setting. This means that the laboratory should not only aim at transferring its technology to the field, but also accompany field studies and large-scale control trials or community-based application programmes. In this context accompanying means: (i) continuous validation of the technology established in the laboratory within different endemic settings, (ii) the application of the technologies in the evaluation and monitoring of disease control programmes, and (iii) attempts to integrate these technologies into the existing health care delivery systems.

The latter element implies that laboratory science has to adapt continuously to the changing structures of health care delivery services, particularly in areas where $\mathrm{PHC}$ strategies are being implemented. The concept outlined also means that the move from the bench to the field should address three levels of operational possibilities that should be well understood by both the laboratory scientists and the different field research cadres in order to achieve sustainable application of newly developed technologies.

\section{1st Level}

Asking the question, 'does it work?', i.e. evaluating efficacy, including the question of how long efficacy is maintained, which is important for booster/ retreatment strategies.

\section{2nd Level}

Addressing the issue of 'how is it to be applied?', i.e. evaluating the effectiveness of a strategy in practice within a given endemic setting.

\section{3rd Level}

Addressing the crucial issue of "how much does it cost?', i.e. evaluating the efficiency of one disease control strategy compared to other options.

\section{CASE STUDIES}

Examples from experience in Tanzania in the field of schistosomiasis will be used to illustrate how the move from the bench to the field - as well as the feedback from the field back to the laboratory - is more successful if this interplay operates at the three levels mentioned above. The examples will focus on three major areas: (i) establishing public health priorities, (ii) the application of control measures at community level, and (iii) the evaluation and monitoring of control measures at community level and within existing health services.

\section{Priorities in public health}

The setting of priorities in the health sector is often a reflection of international health goals, with no direct link to locally prevailing problems. Feachem, Graham \& Timaeus (1987) carefully reviewed this issue. They defined a health problem as 'a state of illhealth which gives rise to non-trivial costs and negative consequences'. This definition has three major implications for those attempting to control parasitic infections within PHC. Firstly, in order to assess the priorities in a given area we need to examine who bears the consequences (including costs) of ill-health. Clearly this has implications both for the planning level (Ministry or district authorities) and, at the other end of the spectrum, for the individual and the household. Secondly, the approach does not only need to include biomedical measurements on, for example, infection rates and morbidity patterns, but should also reflect the perception of health and disease by the population concerned (Jackson, 1985; Heggenhougen \& Shore, 1986; Tanner $\&$ de Savigny, 1987). To study this, we have to adopt a community-based focus.

Thirdly, acceptance of the first two elements leads to approaches that give priority to health problems at the district level on the basis of community-/districtbased health information systems. Although there has recently been a clear move towards decentralized health management and health information strategies (Vaughan, Mills \& Smith, 1984; WHO, 1984, 1987, 1988), we still lack any significant experience concerning health status data use at district level. Analyses of the process of health policy formulation are available but there are no sound case studies that have revealed which health information has actually been used in setting priorities for health and development problems at district level, and how this information is introduced into local planning processes (reviewed by Feachem et al. $198 \overline{7}$ and Tanner 1988). This, however, remains the crucial issue when aiming at an integration of disease control within PHC.

Faced with this situation, we attempted to establish the health and development priorities of a 
Table 1. Summary table ranking the top five health problems of Kikwawila village (Kilombero district, Tanzania) in 1984

(Household-based interviews, the registers of the village health post (VHP) and individual health problems established by one standardized question, are compared with the clinical and parasitological findings. (Based on data from Degrémont et al. 1987 and Tanner et al. 1987b.))*

\begin{tabular}{|c|c|c|c|c|c|}
\hline $\begin{array}{l}\text { Approach } \dagger \ldots \\
\text { Rank }\end{array}$ & $\begin{array}{l}\text { A } \\
\text { Household-based } \\
\text { interviews }\end{array}$ & $\begin{array}{l}\text { B } \\
\text { VHP-register }\end{array}$ & $\begin{array}{l}\text { C } \\
\text { Major individual } \\
\text { health problem }\end{array}$ & $\begin{array}{l}\text { D } \\
\text { Clinical } \\
\text { examination }\end{array}$ & $\begin{array}{l}\text { E } \\
\text { Parasitological } \\
\text { examination }\end{array}$ \\
\hline $\begin{array}{l}(1) \\
(2) \\
(3) \\
(4) \\
(5)\end{array}$ & $\begin{array}{l}\text { Fever/Malaria } \\
\text { Headache } \\
\text { Abdominal pain } \\
\text { Others } \\
\text { Schistosomiasis }\end{array}$ & $\begin{array}{l}\text { Fever/Malaria } \\
\text { Wounds } \\
\text { Headache } \\
\text { Abdominal pain } \\
\text { Cough/Chest }\end{array}$ & $\begin{array}{l}\text { Abdominal pain } \\
\text { Fever/Malaria } \\
\text { Headache } \\
\text { Schistosomiasis } \\
\text { Cough }\end{array}$ & $\begin{array}{l}\text { Splenomegaly } \\
\text { Caries } \\
\text { Skin diseases } \\
\text { Malnutrition } \\
\text { Eye diseases }\end{array}$ & $\begin{array}{l}\text { Malaria } \\
\text { Hookworm } \\
\text { S. haematobium } \\
\text { Strongyloides } \\
\text { G. lamblia }\end{array}$ \\
\hline
\end{tabular}

* The questionnaires were established and validated by a Tanzanian medical sociologist, and all questions were asked in Swahili by local collaborators or village health workers. 'Others' include a wide range of problems not grouped in one of those mentioned. 'Schistosomiasis' also includes statements on dysuria and haematuria (for all details see Degrémont et al. 1987 and Tanner et al. 1986, 1987a,b).

$\dagger$ A. Sample of 1148 villagers $\geqslant 6$ years of age.

B Mean frequency of all 1984 VHP reports used for ranking; 20-30 attendances/working day (6/week).

C-E. Data established by annual health status surveys among all children ( 1 month to 15 years) of Kikwawila village during dry season; 588 children included in 1984. For clinical findings the ranking is based on point prevalences, for parasitological findings the ranking is based on a composite measure of point prevalences and intensity of infection, except for malaria where endemicity was assessed using parasite and spleen rates.

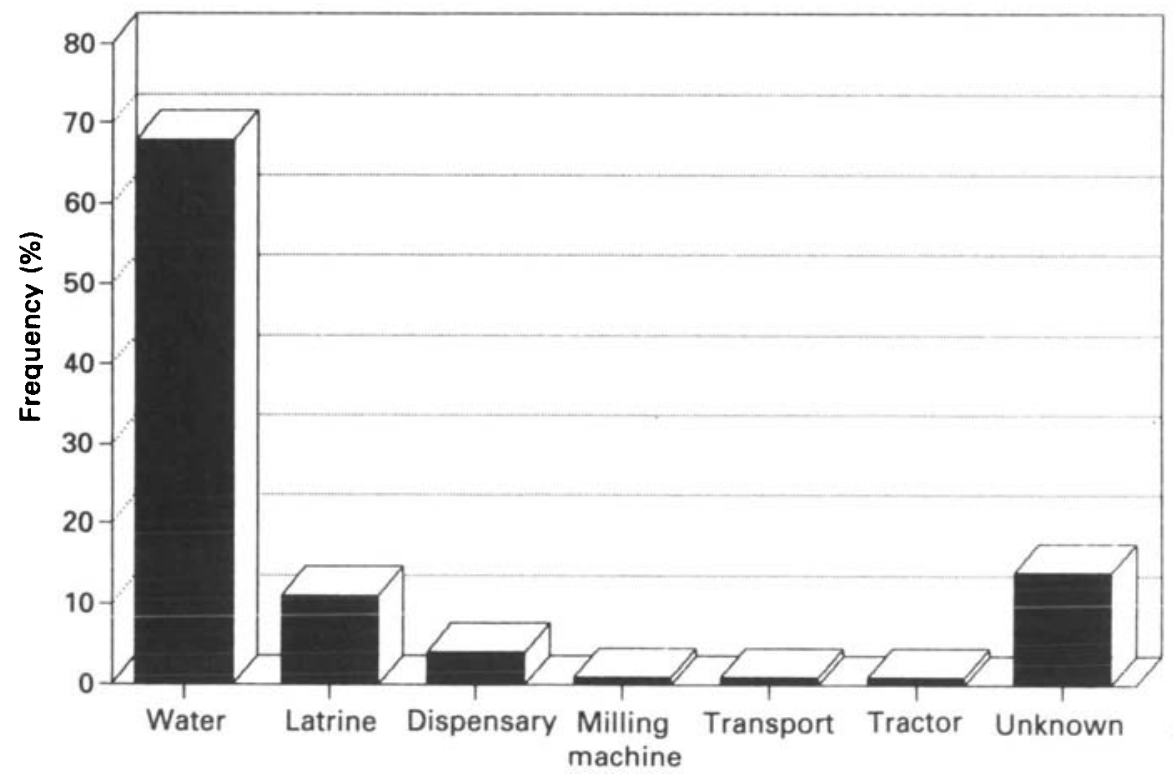

Fig. 1. Priorities of Kikwawila village (Kilombero District, Tanzania). Answers from a sample of 841 adults interviewed at household level (based on data from Tanner et al. 1986).

community, Kikwawila village, in south-eastern Tanzania. Table 1 (based on data obtained by Degrémont et al. 1987 and Tanner et al. $1987 \mathrm{~b}$, 1989) summarizes the results of various approaches that were used. (A) An interview at the household level among inhabitants ( $>6$ years of age) on the most important health problems was undertaken by a medical sociologist not belonging to the district health or the research team. This was used to rank health problems. (B) An analysis of the village health post registers completed by the village health workers (VHW) (STIFL, 1985; Tanner et al.
$1987 a$ ). (C) A health interview during the yearly community health status surveys asking children (1 month-15 years of age) or their caretakers for their major individual health problem during the previous month.

These questionnaire approaches were compared with the results from clinical and parasitological examinations of children and adults within the same population (detailed results reported by Tanner et $a l .1987 b$ and Degrémont et al. 1987). Although there is an overall agreement between the conclusions from the different approaches concerning 


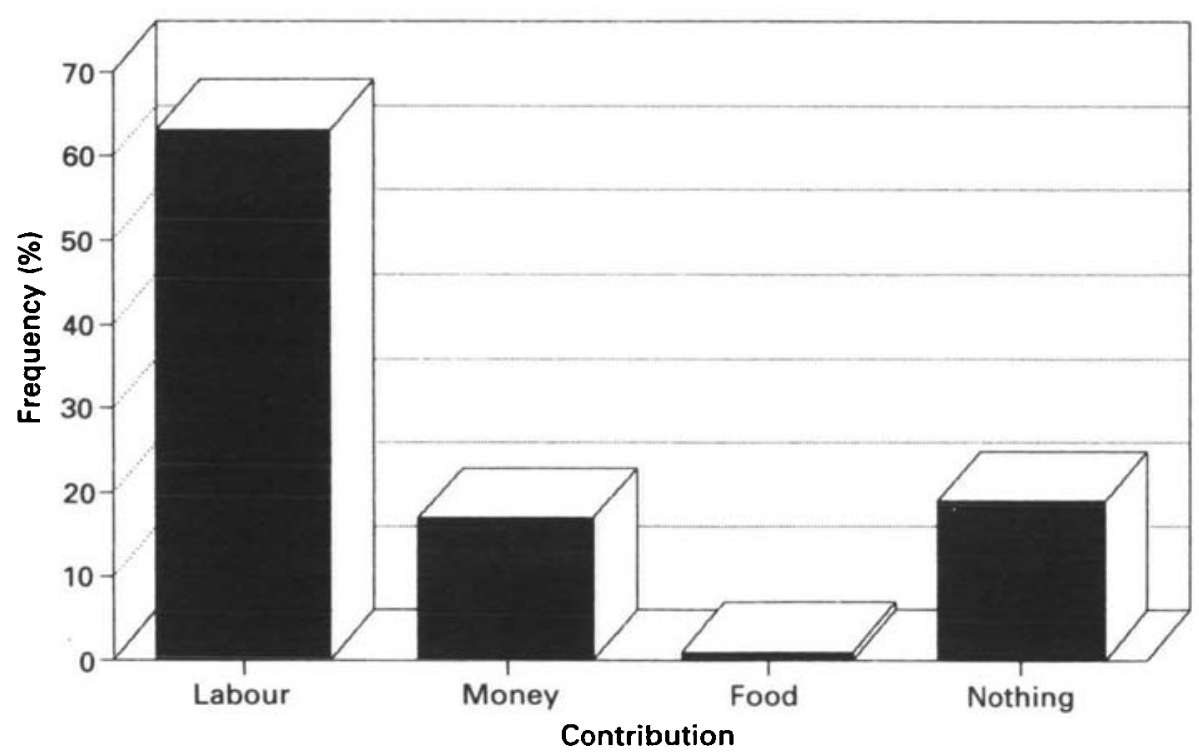

Fig. 2. What villagers of Kikwawila (Kilombero District, Tanzania) would contribute to solve the village priority problems; answers from a sample of 833 adults (based on data from Tanner et al. 1986). Labour work for village projects; Money - pay for village projects; Food-food for workers in village.

malaria and the complex of intestinal parasitoses, important elements affecting the health of a community, such as skin disease and nutritional problems, were only revealed by the clinical surveys and not perceived by the population.

When health problems were assessed within the frame of all community development problems as perceived by adult villagers (Fig. 1) they were not ranked first; essential infrastructure/commodities such as tap water supply and sanitation were the most pressing issues.

We asked the same sample of adults if and how they might be able to contribute to achieving these community development priorities. Fig. 2 shows the answers and reveals that a majority is willing to work for the common projects, while others wished to provide money for a community project or food for the workers. It was interesting to note that only $19 \%$ did not feel they could contribute anything.

Using this information on how the biomedical measurements and the community perceptions ranked health and development problems (Table 1, Figs 1-2), it was possible to structure the steps to be undertaken in disease control measures. In this area, schistosomiasis showed substantial schistosome-related bladder and kidney pathology with relatively low egg-output (Degrémont et al. 1985 ; Burki et al. 1986). Clearly, the starting-point for intervention against schistosomiasis was the planning and implementation of a gravity water-supply scheme connected with a latrine campaign. These construction schemes relied heavily on the community's readiness to provide labour (cf. Fig. 2). It was only after these long-term strategies, which matched community priorities (Fig. 1), had been introduced to and accepted by the villagers, that other interventions were launched, such as selective mass- treatment, focal application of molluscicides and health information/education campaigns. This sequence of events, initially determined by community health priorities, created a sound foundation for community involvement and participation, a prerequisite of PHC approaches (Tanner et al. 1986; Tanner \& de Savigny, 1987). As experienced in Kikwawila and as many other PHC projects have shown (Morley et al. 1983), implementation of control strategies, even when these develop out of participatory processes of prioritization and planning, is crucially dependent on the social and political anatomy of a community, particularly the leadership structure. This remains a key issue for the sustainability of any health project.

This approach - using both the community's assessment of health priorities and biomedical measurements of ill-health - proved to be highly successful in one community. However, it would be too expensive and time-consuming to apply it to a larger area. We therefore attempted to develop a simpler procedure for identifying high-risk communities for urinary schistosomiasis in the whole of the Kilombero District; an area in which the local authorities regard the disease as an important problem.

The Kilombero District extends over $14918 \mathrm{~km}^{2}$ and has approximately 180000 inhabitants (1986) living in 49 villages (including the district capital and its town suburb areas). Table 2 summarizes the approaches that were compared; (i) the examination of the routine data collection of the health centres and dispensaries, (ii) questionnaires sent through the channels of the ruling party to all village chairmen, (iii) questionnaires sent through the channels of the district education office to all headteachers (total of 77 schools) as well as (iv) simplified questionnaires for the students of the standards 1,3 and 5 which 
Table 2. Comparison of different approaches to identify Schistosoma haematobium high-risk villages in Kilombero district, Tanzania

(Based on Lengeler et al. in preparation)

\begin{tabular}{|c|c|c|c|c|c|}
\hline \multicolumn{2}{|c|}{ Approach } & \multirow{2}{*}{$\begin{array}{l}\text { Source } \\
\begin{array}{l}\text { Health centre } \\
\text { dispensary reports }\end{array}\end{array}$} & \multirow{2}{*}{$\frac{N}{19}$} & \multirow{2}{*}{$\begin{array}{l}\begin{array}{l}\text { Percentage } \\
\text { returned }\end{array} \\
100\end{array}$} & \multirow{2}{*}{$\begin{array}{l}\text { Within } \\
\text { months }\end{array}$} \\
\hline (i) & Health statistics & & & & \\
\hline (ii) & CCM questionnaire ${ }^{3 *}$ & Village chairmen & $\begin{array}{l}39 \\
(47 \text { villages }) \dagger\end{array}$ & 83 & 3 \\
\hline (iii) & Teacher questionnaire & Head teachers & $\begin{array}{l}77 \\
(77 \text { schools) }\end{array}$ & 100 & 1 \\
\hline (iv) & Student questionnaire & $\begin{array}{l}\text { Standard } 1,3 \text { and } \\
\text { 5 f students }\end{array}$ & $\begin{array}{l}7118 \\
(73 / 77 \text { schools })\end{array}$ & 95 & 1 \\
\hline (v) & Mobile laboratory & $\begin{array}{l}\text { Standard } 3 \downarrow \\
\text { students }\end{array}$ & $\begin{array}{l}4560 \\
(54 \text { schools }) \S\end{array}$ & 100 & 3 \\
\hline
\end{tabular}

* Questionnaires sent through party channels to all villages where the chairman/secretary answered.

$\dagger 47 / 49$ villages approached, 2 town suburbs not included.

I Only students of the standards indicated and present during day of survey were included.

$\S$ Only 54/77 schools were selected for validation surveys.

accompanied the ones sent to the headteachers (iii). All questionnaires were written in Swahili and were extremely short. Those for village chairmen and headteachers had six questions; the ranking of the diseases most prevalent in the area; the ranking of the most prevalent symptoms and signs, and the ranking of the health and development priorities of the village, and the available health services and water supply. Students' questionnaires only focused on three issues, including the diseases, symptoms and signs experienced during the last month and whether they had made use of the health services during the last month. It should be stressed that the questionnaires did not specifically address schistosomiasis and schistosome-related morbidity symptoms and signs.

These approaches were subsequently validated by a mobile laboratory team (v) using urine filtration for egg counts and dip-stick tests for a semi-quantitative assessment of microhaematuria. The comprehensive description of the approaches and a detailed análysis of the results are to be found in a series of publications in preparation (Ph.D. thesis Lengeler, Lengeler et al. in preparation). In summary, the comparison of the different approaches revealed that questionnaires on health-related issues sent through well-established channels outside the health sector (party, education office) showed a remarkably high coverage and fast return rates (Table 2). The best coverage and correlation with the parasitological results and indirect morbidity parameters (microhaematuria) were found with the questionnaires completed by the headteachers. This approach showed a sensitivity of $85 \%$ in the high morbidity villages (as defined by a composite measurement combining prevalence, intensity and haematuria based on the findings of the mobile laboratory) and a specificity of $94 \%$ in the low morbidity villages.
When all villages were combined, the sensitivity was $85 \%$ and the specificity $69 \%$, resulting in a positive predictive value of $57 \%$ and negative one of $90 \%$. The questionnaires answered by the village chairmen and the students gave sensitivities between 40 and $45 \%$ and specificities between 95 and $99 \%$. All these data clearly indicate that villages where urinary schistosomiasis does not represent a major public health problem can be very reliably identified by the questionnaire approach, and this approach can also identify those villages where prevalence and morbidity of urinary schistosomiasis needs to be further investigated. Recently, this approach via the district education office and the headteachers has been validated in the neighboring Kilosa district involving 168 schools and 15022 students. In addition, the approach has been extended to a stage where teachers apply dip-sticks to assess haematuria among children of schools in high-risk areas identified by the questionnaires.

The comparison of these approaches shows us how carefully established laboratory techniques, urine filtration using re-usable filters and chemical reagent strips (dip-sticks), that have been validated in the field (Mott, Dixon \& Osei-Tutu, 1985), can be used for large-scale district-based application. It also points at their importance in validating new approaches that are based on indirect morbidity measurements and ill-health perception patterns.

However, the most important conclusion is perhaps that the comparison illustrates the development, validation and establishment of diagnostic strategies in public health that are cost-effective. For example, the headteacher questionnaire approach using existing administrative structures costs around US\$1 per school compared to US\$110 (1987 rates) for the mobile laboratory. Such diagnostic strategies may be of great importance for the development of 


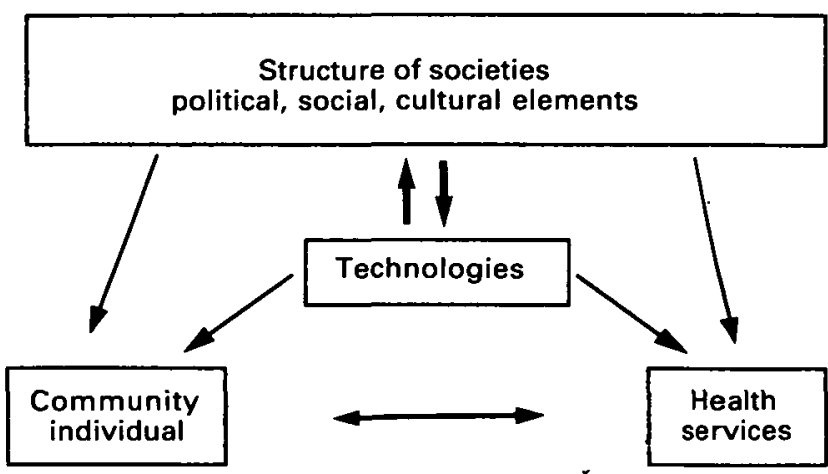

Fig. 3. Determinants of technology transfer; the interactions between the features of the society, the health system, the community and the technology to be transferred (based on data from Bonair et al. 1989).

regional and national control programmes. It is well understood that the validity of the questionnaire approach needs to be monitored again after interventions have taken place in the initially identified high-risk villages; interventions of any kind and their interaction with the community may well substantially change disease perception and attitudes towards health and health services and, thus, the need/demand pattern. Finally, this example of the establishment of public health priorities relied heavily on intersectorial collaboration through its interaction with party channels, district administration and education offices. Such collaboration is essential if a PHC approach is to function.

\section{Application of control measures at community level}

Once the communities with high endemicity and morbidity of urinary schistosomiasis have been identified, interventions should follow. The previous section indicated how this was put into practice in Kilombero. Community priorities such as the demand for safe water and sanitation were used as an entry-point for intervention. Besides these longterm control measures, short-term interventions like chemotherapy and molluscicide application could also be applied. The VHW, together with the village leaders, were efficient in mobilizing the community to seek treatment and in providing comprehensive information on the disease, its impact and the interventions planned. This made it possible to launch selective mass chemotherapy campaigns in the dry season, just before transmission would start again.

In addition, a local plant molluscicide was developed and successfully applied (Suter et al. 1986; Suter, 1986). This is an example of the interaction between laboratory and field work leading to a community-based intervention (Figs 4-8). The molluscicide is extracted from the seed pods of a tree, Swartzia madagascariensis (Desv.; Leguminosae), which is widespread in tropical Africa (Brenan, 1967) and is well known to the local population as medicine for a variety of purposes (Watt \& Breyer-Brandwijk, 1962). In the Kilombero valley, the fruits (seed pods), have been used for fishing for many years. Its potential as a molluscicide was mentioned by Mozely (1939). In view of this, and of the fact that the tree was common in the schistosomiasis endemic area, it seemed promising to investigate it further, especially as studies on the distribution, population dynamics and breeding sites of the intermediate host snails, Bulinus globosus, had suggested that focal application of molluscicides could be a practicable control measure. During the dry season, oviposition was concentrated in clearly defined sites, so-called 'breeding pockets', from which the snails spread when these sites were flooded during the following rainy season (Marti et al. 1985; Marti, 1986). The 'breeding pockets', and the potential transmission sites, were all located along small streams used by the local population for domestic and recreational purposes, but not for fishing. This suggested that in this endemic setting the control of urinary schistosomiasis could be approached by focal mollusciciding of these 'breeding pockets', in combination with vegetation clearing and the other measures mentioned earlier.

In a highly interactive research process involving biologists, chemists, pharmacists, social scientists, epidemiologists, VHW, the villagers and their leaders, laboratory and field trials were undertaken to establish the best way of harvesting and storing, grinding and extracting $S$. madagascariensis pods, and the best method and frequency for applying the extract to the 'breeding pockets' and potential transmission sites (Lwihula, 1985; Suter et al. 1986; Tanner et al. 1986; Borel \& Hostettmann, 1987). The cycle led from local suggestions about the potential of the seed pods to the identification and description of the molluscicidic components, the saponins, and then back to the members of the community who could prepare the molluscicide using their mortars (normally used to grind maize and rice) and river water for the extraction of the pods (Suter et al. 1986).

Detailed studies showed that the saponin responsible for the molluscicidal activity had a toxicity of LC 100 at $3 \mathrm{mg} / \mathrm{l}$ after exposure of Bulinus globosus and Biomphalaria spp. for $24 \mathrm{~h}$. The saponin could be identified by FAB-MS and ${ }^{13} \mathrm{C}-\mathrm{NMR}-$ spectroscopy as oleanolic acid-3-O- $\beta$-D-glucuronopyranosyl $(1 \rightarrow 3)-\alpha$-L-rhamnopyranoside (Fig. 6; Suter et al. 1986; Borel \& Hostettmann, 1987). Parallel to these field and laboratory studies, the assessment of the mutagenicity and toxicity of the pod extracts against non-target organisms was initiated. Moreover, the careful observation of human water contact activities, by VHW and other villagers, enabled the focal application of the extracts during the dry season when water quantities were low. 

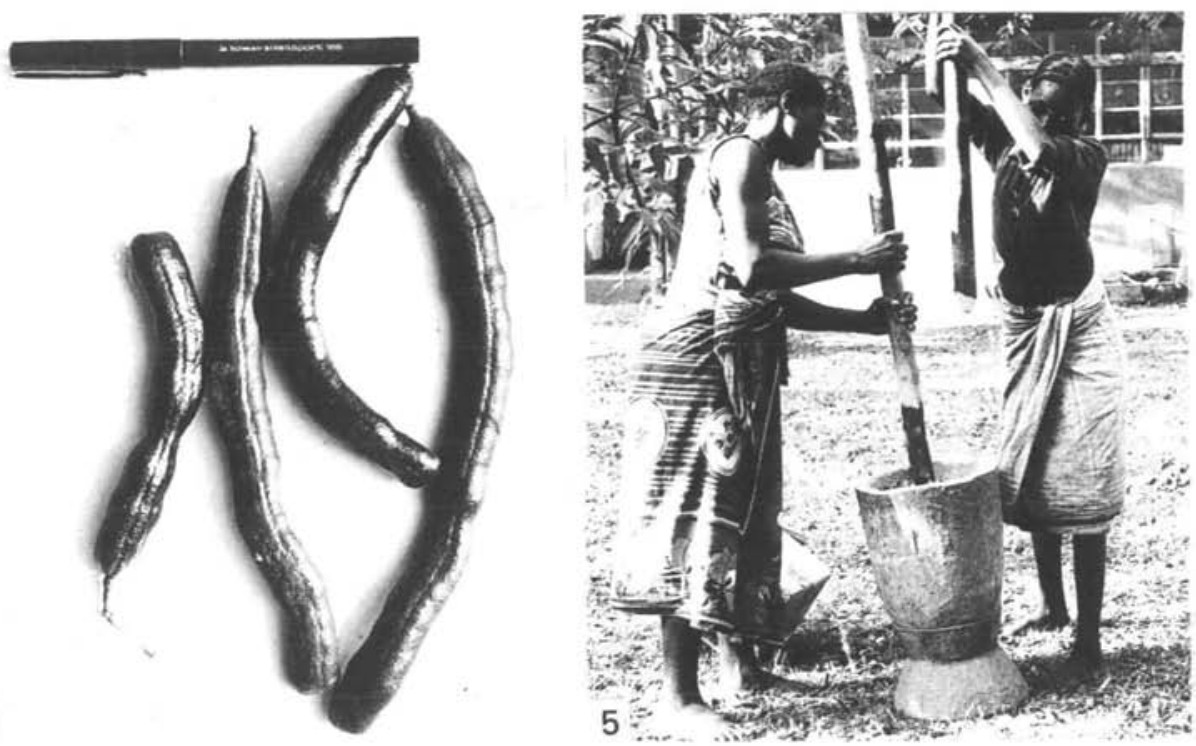

6

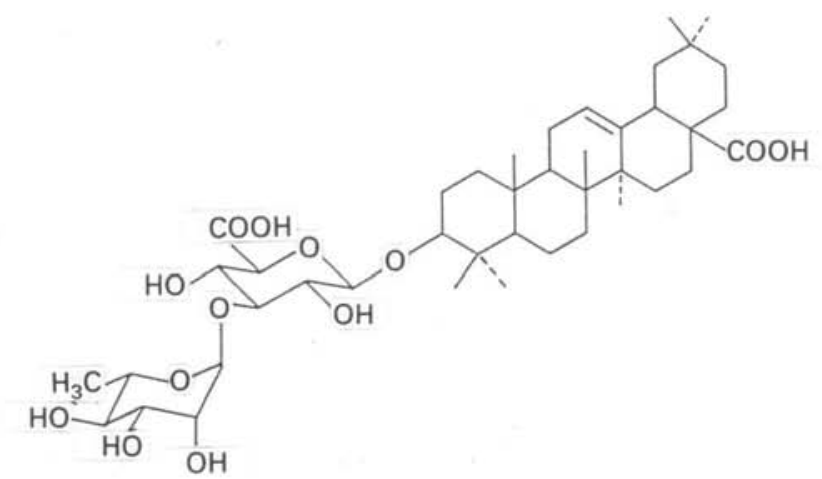
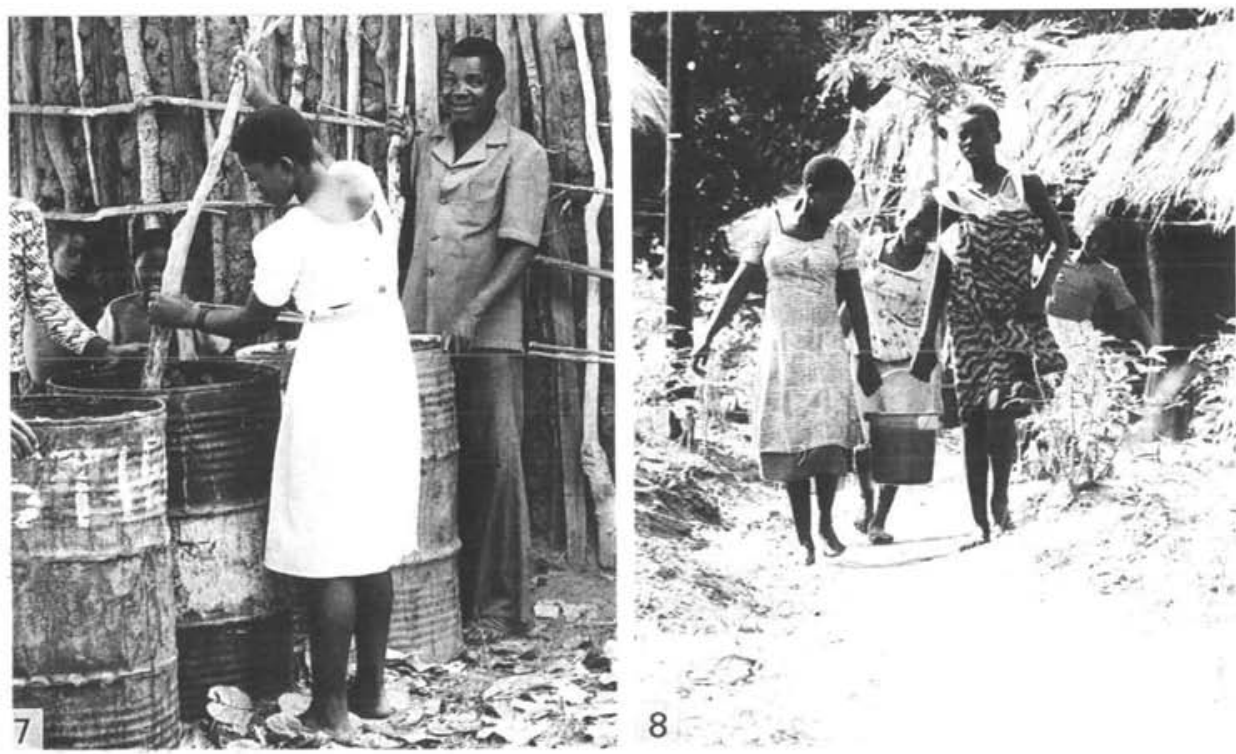

Figs 4-8. The plant molluscicide Swartzia madagascariensis (Desv.); from laboratory and field research to the community-based application in potential transmission sites in Kilombero district. Tanzania.

Fig. 4. Mature seed pods of S. madagascariensis; a mature tree yields approximately $30 \mathrm{~kg}$ of dry pods. Fig. 5. Preparation of ground pods using a local mortar. Fig. 6. Structural formula of oleanolic acid-3-O- $\beta$-Dglucuronopyranosyl $(1 \rightarrow 3)$ - $\alpha$-L-rhamnopyranoside (Suter et al. 1986; Borel \& Hostettmann, 1987), the saponin isolated from seed pods of $S$. madagascariensis and exerting the molluscicidal activity against Bulinus sp. and Biomphalaria sp. Fig. 7. Extraction of ground $S$. madagascariensis pods using river water $(40 \mathrm{~g} / 1$ for $24 \mathrm{~h}$ ) and used drums; except for the initial dosing, the work is done by villagers. Fig. 8 . Villagers carry $S$. madagascariensis extracts to the potential transmission sites for application under the supervision of village health workers and health project staff. 
The evaluation of these efforts showed a substantial reduction of the population densities of infected and non-infected $B$. globosus and also of the densities of furcocercariae in the potential $S$. haematobium transmission sites. There was also a marked reduction in the incidence of $S$. haematobium infections among the children and adults frequenting these river sites (Suter, 1986). These low levels of transmission have so far been maintained for 2 years. Besides illustrating the collaboration between field and laboratory scientists with PHC workers and villagers, this example represents a move towards a successful technology transfer, involving interactions between health system, social, technological and individual factors (Fig. 3). The necessity for such interaction was extensively discussed in the authoritative review by Bonair, Rosenfield \& Tengvald (1989).

\section{Evaluation and monitoring}

The evaluation and monitoring of control activities are pre-requisites for the successful maintenance of initially achieved reductions in transmission and/or morbidity levels. A review of the literature reveals that this essential component is lagging behind many important developments made in the field of diagnosis and treatment. In schistosomiasis, control approaches have undergone substantial conceptual changes (Mott, 1987; Cook, 1987) and effective safe drugs and simple diagnostic tools have become available that facilitate community-based actions (Mott, 1984). The objectives of control have shifted from transmission control to the control of schistosome-related disease, i.e. morbidity control. This shift, however, has not been accompanied by changes in the way in which control procedures are evaluated and monitored. Also, little attention has been paid to the choice of appropriate (relating to the objectives of control) indicators for evaluation and monitoring, and to which part of the existing health care delivery structures could perform these activities. Comprehensive reviews of the potential and needs for monitoring and evaluation in health care have been compiled (Holland, 1983; Feuerstein, 1986) and extended to parasitic disease control (Tanner, 1989).

Laboratory workers who aim at an application of their results in the field often focus their efforts on the impact of an intervention. Impact assessment in control activities, is, however, the last of many levels that should be investigated, and its results represent a composite measure not necessarily fully and/or directly related to the initial objectives and inputs. At the application stage of control measures, particularly when new approaches are being validated in the field, evaluation should focus on 5 levels: the inputs (staff, infrastructure, drugs, finances), the process (the elements describing the immediate implementation), the output (availability of drugs and presence of staff), the effects and coverage representing the outcome (e.g. \% treated, \% sites molluscicide applied, $\%$ villages health education delivered) and finally the impact (change of incidence, reduction of morbidity). More comprehensive discussions of the various levels of evaluation have been published elsewhere (WHO, 1983; Tanner, 1989). Each level of evaluation requires its set of indicators. It is this element that needs our careful consideration when aiming at an integration of control measures into existing health services based on PHC principles. Table 3 summarizes possible indicators that can be applied to evaluating and monitoring schistosomiasis and malaria control activities. It also attempts to review the applicability of the various indicators for their use in health care programmes emphasizing $\mathrm{PHC}$ or within special - 'vertical' - disease control programmes such as those of the WHO. The table does not aim at a comprehensive picture, and the rating of applicability is based on the assumption that the diseases malaria and/or schistosomiasis represent a major factor of ill-health in the particular area concerned (see also Priorities in public health section), and that the health services rely on PHC principles emphasizing VHW. Clearly, an initial assessment of the public health priorities will allow the integration of evaluation and monitoring activities into existing health services and prevent PHC workers and other community members from being overloaded by nonpriority tasks.

Examination of Table 3 reveals that there exist many possible indicators for each level of evaluation and for both malaria and schistosomiasis control, which relate to operationally and epidemiologically relevant parameters. However, it has to be noted that, although most of these indicators have been successfully used in small-scale or pilot operations (for schistosomiasis summarized by: Tanner \& Degrémont, 1986; Tanner, 1989, for malaria by: Brown, 1988), most of them still have to undergo careful standardization and large-scale field validation before they can be efficiently applied for intra-programme and inter-programme comparison. Nevertheless, Table 3 shows that a considerable potential exists for the integration of a substantial part of evaluation and monitoring activities into existing PHC structures, i.e. VHW and other community members can become actively involved in securing the maintenance phase of disease control operations once the initial attack phase with substantial special programme/team support is completed. Morbidity control activities can be particularly well monitored at community level, since there are a number of promising direct and indirect morbidity indicators that have a high predictive power and do not require sophisticated techniques; for example haematuria, and perception of other 
Table 3. Evaluation and monitoring of schistosomiasis and malaria control; potential indicators and their applicability within existing health services and/or special programmes/teams

(Summary based on data from Brown, 1988 and Tanner, 1989.)

\begin{tabular}{|c|c|c|}
\hline \multirow{2}{*}{ Indicator } & \multicolumn{2}{|c|}{ Applicability within } \\
\hline & PCH system* & Control programme \\
\hline \multicolumn{3}{|l|}{ Schistosomiasis } \\
\hline \multicolumn{3}{|l|}{ Man } \\
\hline Incidence/reinfection & $(+)$ & ++ \\
\hline Intensity & + & ++ \\
\hline Morbidity $\dagger$ direct & $\mathbf{0}$ & ++ \\
\hline indirect & $+t$ & + \\
\hline Compliance treatment & ++ & + \\
\hline Side-effects treatment & + & + \\
\hline Compliance, other measures $\ddagger$ & + & $(+)$ \\
\hline Behavioural changes & ++ & $(+)$ \\
\hline Acceptability of programme & ++ & $(+)$ \\
\hline \multicolumn{3}{|l|}{ Snails } \\
\hline Densities & ++ & ++ \\
\hline Infection rates & 0 & ++ \\
\hline \multicolumn{3}{|l|}{ Sites } \\
\hline Cercariometry & 0 & ++ \\
\hline Composite site assessments $\S$ & ++ & + \\
\hline \multicolumn{3}{|l|}{ Malaria } \\
\hline \multicolumn{3}{|l|}{ Man } \\
\hline Infection & + & $+t$ \\
\hline Episodes/attacks\| & ++ & ++ \\
\hline Spleen rates & ++ & ++ \\
\hline Mortality (oral post-mortem) $\|$ & + & ++ \\
\hline Immune response & $(+)$ & ++ \\
\hline Drug consumption & ++ & $(+)$ \\
\hline Use of bednets/curtains 9 & ++ & $(+)$ \\
\hline Behavioural changes & ++ & $(+)$ \\
\hline Acceptability of programme** & $+t$ & $(+)$ \\
\hline \multicolumn{3}{|l|}{ Mosquitoes } \\
\hline Density/species & $(+)$ & ++ \\
\hline Infection rates & 0 & ++ \\
\hline Breeding sites & + & $+t$ \\
\hline Perception of mosquito problem & ++ & $(+)$ \\
\hline
\end{tabular}

* Applicability within special disease control programmes/teams or within routine health services emphasizing primary health care (PHC) and the presence of community or village health workers; based on this distinction the rating of applicability within each column is indicated by the scores $0,(+),+,++$.

$\dagger$ For detailed listing and discussion of direct and indirect morbidity assessment and its indicators see Tanner et al. (1989).

I Other measures include e.g. construction and use of latrines, participation in water supply project, building of safe bathing places or washing slabs etc.

$\S$ Standardized assessment forms (for site structure, presence of human traces/ activities and snails e.g. as proposed by WHO) (Dixon, 1985).

\| Household-based episode recall interviews (Greenwood et al. 1987; Alonso et al. 1987).

I Mainly insecticide-impregnated nets and curtains for doors and windows.

** Includes all measures taken at household/community level ranging from promotion of personal protection to improved housing and chemoprophylaxis schemes.

symptoms and signs in schistosomiasis (Tanner, 1989), or episode recalls and oral post-mortems in malaria (Alonso et al. 1987; Greenwood et al. 1987; Brown, 1988). The routine measurement of these indicators within existing health services could be complemented and supported by special programme/team activities on carefully sampled segments of the population. Sonography for the direct community-based assessment of schistosomerelated morbidity (Degrémont et al. 1985 ; Homeida et al. 1988), and new immunological and entomological tools and approaches to measure immunity 
and exposure to or transmission of malaria (Burkot et al. 1987; Brown 1988; Del Giudice, Grau \& Lambert, 1988; Greenwood, 1988) are examples of such activities.

A high level of integration of evaluation and monitoring activities into existing health services may also ensure more efficient feedback to those concerned, and could thus increase community involvement and strengthen the district focus in PHC implementation. It is necessary to be aware of the outlines provided in Table 3 during introduction of new technologies for the assessment of control activities.

\section{CONCLUSIONS}

This review of the various levels of interaction between laboratory scientists, field workers, PHC cadres and community members has revealed how any step from the bench to the field has to consider the indigenous health perspectives of the community concerned. This not only involves making biomedical measurements, but also requires the involvement of social, economic and anthropological disciplines. This interdisciplinary approach is in fact one of the essential basic principles of PHC (WHO, 1978), and needs to be emphasized in order to prevent PHC from being medicalized (Nichter, 1984; Heggenhougen \& Shore, 1986).

In a given area, PHC implementation initiates a joint action of both clinical and community medicine, involving a decentralization process aiming at, for example, a district focus. Laboratory science not only has to provide new technologies ready to be transferred to the field, but the laboratory should also be concerned with the questions of the continuous validation and standardization of these technologies in the field, and of their applicability within existing health services. This concept entails much more than collecting 'material' (e.g. sera) in endemic areas for analysis in a sophisticated laboratory. It represents an interplay that should prevent field research and its application from lagging behind laboratory achievements. The recent experience in malaria vaccine research (summarized by Hockmeyer \& Ballou, 1988) exemplifies this problem. While a series of highly promising candidate vaccines have been proposed on the basis of laboratory achievements in the field of molecular biology and immunology, we still lack comparative studies assessing the determinants of the immune response of individuals who are naturally and continuously exposed to infectious mosquito bites against these antigens/epitopes in different endemic settings. Malaria vaccine research might have benefited greatly from redirection and adjustment resulting from a parallel development of interactive field and laboratory research.

As we move with great speed and remarkable success towards vaccine development for many parasitic diseases, in the laboratory, we should strengthen and maintain our partnership with the endemic areas; on the one hand with local laboratory and field scientists, and on the other hand with the communities, so that we are aware of their perception of health and disease and of how ill-health should or could be overcome within their particular health care delivery system, which is based on the prevailing social, economic and political determinants. While building this partnership between the bench and the field, we should also strengthen the valuable existing elements, particularly those emerging from communities, i.e. consider the advice of Werner (1980) to stop re-inventing wheels, but get busy helping to roll the existing ones.

The field work in collaboration with the communities of the Kilombero district, their leaders and district authorities, as well as with the staff of the Swiss Tropical Institute in Ifakara and Basel, provided the basis for this paper. I am most grateful for this invaluable experience. Special thanks are due to Antoine A. Degrémont, Don de Savigny, Christoph Hatz, Jennifer Jenkins, Wen Kilama, Christian Lengeler, Charles Mayombana and Hassan Mshinda for stimulating discussions and comments. Reto Suter kindly provided photographs $4,5,7$ and 8 . I wish to thank Silvia Saladin and Urs-Peter Modespacher for their help in preparing the figures and Christine Walliser for her most competent secretarial assistance.

\section{REFERENCES}

ALONSO, P. L., BOWMAN, A., MARSH, K. \& GREENWOOD, B. M. (1987). The accuracy of the clinical histories given by mothers of seriously ill African children. Annals of Tropical Paediatrics 7, 187-9.

BONAIR, A., ROSENFIELD, P. \& TENGVALD, K. (1989). Medical technologies in developing countries: issues of technology development, transfer, diffusion and use. Social Science and Medicine (in the Press).

BOREL, CH. \& HOSTETTMANN, K. (1987). Molluscicidal saponins from Swartzia madagascariensis (Desvaux). Helvetica Chimica Acta 70, 570-6.

BRENAN, J. P. M. (1967). Leguminosae, subfamily Caesalpinoidae. In Flora of Tropical East Africa (ed. Milne-Redhead, E. \& Polhill, R. M.), pp. 218-20.

London: Crown Agents for Overseas Governments. Brown, G. (1988). Assessment of immunity (protection) against malaria. Working Paper for Foint FIELDMAL/IMMAL Meeting on Immunological Aspects of Malaria Epidemiology. Geneva : WHO/TDR documents (n/d).

BURKI, A., TANNER, M., BURNIER, E., SCHWEIZER, W., MEUDT, R. \& DEGRÉMONT, A. A (1986). Comparison of ultrasonography, intravenous pyelography and cystoscopy in detection of urinary tract lesions due to Schistosoma haematobium. Acta Tropica 43, $139-51$. BURKot, T. R., GRAVES, P. M., CATTANI, J. A., WIRTZ, R. A. \& GIBSON, F. D. (1987). The efficiency of sporozoite transmission in the human malarias, Plasmodium falciparum and P. vivax. Bulletin of the World Health Organization 65, 375-80.

cook, J. A. (1987). Strategies for control of human 
schistosomiasis. In Schistosomiasis (ed. Mahmoud, A. A. F.). Clinical Tropical Medicine and Communicable Diseases 2, 449-63.

DEGRÉMONT, A. A., BURKI, A., BURNIER, E., SCHWEIZER, W., MEUDT, R. \& TANNER, M. (1985). Value of ultrasonography in investigating morbidity due to Schistosoma haematobium infection. Lancet i 662-5

DEGRÉMONT, A., LWIHULA, G. K., MAYOMBANA, CH., BURNIER, E., DE SAVIGNY, D. \& TANNER, M. (1987).

Longitudinal study on the health status of children in a rural Tanzanian community: comparison of community-based clinical examinations, the diseases seen at village health posts and the perception of health problems by the population. Acta Tropica 44, 175-90.

DEL GIUDiCE, G., GRAU, G. E. \& LAMBERT, P. H. (1988).

Host responsiveness to malaria epitopes and immunopathology. In Malaria Immunology (ed. Perlmann, P. \& Wigzell, H.). Progress in Allergy 41 , 288-330. Basel: Karger.

DIXON, H. (1985). Statistical methods applicable to schistosomiasis control programmes. $\dot{W H O} / S C H I S T O / 85.81$ and WHO/ESM/85.1 (unpublished document).

FEACHEM, R. G., GRAHAM, W. J. \& TIMAEUS, I. (1987). Identifying health problems and health research priorities in developing countries. Background paper for the Independent International Commission on Health Research for Developing Countries. London.

FEUERSTEIN, M.-T. (1986). Partners in Evaluation, Evaluating Development and Community Programmes with Participants. London: Macmillan.

GREENWOOD, B. M. (1988). Correlation between immune response to $P$. falciparum and protection and their development in human populations. Working Paper for foint FIELDMAL/IMMAL Meeting on Immunological Aspects of Malaria Epidemiology. Geneva: WHO/TDR documents (n/d).

GREENWOOD, B. M., BRADLEY, A. K., GREENWOOD, A. M., BYASS, P., JAMEH, K., MARSH, K., TULLOCH, S., OLDFIELD, F. S. J. \& HAYES, R. (1987). Mortality and morbidity from malaria among children in a rural area of The Gambia, West Africa. Transactions of the Royal Society of Tropical Medicine and Hygiene 81, 478-86.

HEGGENHOUGEN, H. K. (1984). Will primary health care efforts be allowed to succeed? Social Science and Medicine 19, 217-24.

HEGGENHOUGEN, H. K. \& SHORE, L. (1986). Cultural components of behavioral epidemiology: implications for primary health care. Social Science and Medicine $22,1235-45$.

HOCKMEYER, W. T. \& BALloU, w. R. (1988). Sporozoite immunity and vaccine development. In Malaria Immunology (ed. Perlmann, P. \& Wigzell, H.) Progress in Allergy 41, 1-14. Basel: Karger.

HOLland, w. w. (1983). Evaluation of Health Care. Oxford: Oxford University Press.

HOMEIDA, M. A., AHMED, S., DAFALla, A., SUliman, S., ELTOM, I., NASH, T. \& BENNETT, J. L. (1988). Morbidity associated with Schistosoma mansoni infection as determined by ultrasound: a study in the Gezira, Sudan. American Yournal of Tropical Medicine and Hygiene (in the Press).

JACKSON, L. C. (1985). Malaria in Liberian children and mothers: biocultural perceptions of illness vs clinical evidence of disease. Social Science and Medicine 20, 1281-7.

LWIHULA, G. K. (1985). Human behavior factors associated with transmission and control of Schistosoma haematobium in the Ifakara area, Morogoro, Tanzania. Ph.D. thesis, University of London.

MARTI, H. P. (1986). Field observations on the population dynamics of Bulinus globosus, the intermediate host of Schistosoma haematobium in the Ifakara area, Tanzania. Journal of Parasitology 72, 119-24.

MARTI, H. P., TANNER, M., DEGRÉMONT, A. A. \& FREYVOGEL, T. A. (1985). Studies on the ecology of Bulinus globosus, the intermediate host of Schistosoma haematobium in the Ifakara area, Tanzania. Acto Tropica 42, 171-87.

MORLEY, D., ROHDE, J. \& Williams, G. (1983). Practising Health for All. Oxford, New York and Toronto: Oxford University Press.

MOTT, к. Е. (1984). Schistosomiasis; a primary health care approach. World Health Forum 5, 221-5.

MOTT, K. E. (1987). Schistosomiasis control. In The Biology of Schistosomes : from Genes to Latrines (ed. Rollinson, D. \& Simpson, A. J. G.), pp. 431-50. London: Academic Press.

MOTT, K. E., DIXON, H. \& OSEI-TUTU, E. (1985). Evaluation of reagent strips in urine tests for detection of Schistosoma haematobium infection; a comparative study in Ghana and Zambia. Bulletin of the World Health Organization 63, 125-33.

MOZELY, A. (1939). Fresh water mollusca of the Tanganyika Territory and the Zanzibar Protectorate, and their relation to human schistosomiasis. Transactions of the Royal Society, Edinburgh 59, 687-730.

NICHTER, M. (1984). Project community diagnosis: participatory research as a first step towards community involvement in primary health care. Social Science and Medicine 19, 237-52.

STIFL (SWISS TROPICAL INSTITUTE FIELD LABORATORY) AND DISTRICT HEALTH OFFICE (1985). Collaborative primary health care project in Kilombero District, Tanzania. Working Document STIFL No. 1.

SUTER, R. (1986). The plant molluscicide Swartzia madagascariensis and its application in transmission control measures against Schistosoma haematobium; experience from Kikwawila (Kilombero district, Tanzania). Ph.D. thesis, University of Basel.

SUTER, R., TANNER, M., BOREL, CH., HOSTETTMANN, K. \& FREYVOGEL, T. A. (1986). Laboratory and field trials at Ifakara (Kilombero district, Tanzania) on the plant molluscicide Swartzia madagascariensis. Acta Tropica 43, 69-83.

TANNER, M. (1988). District-level data collection and use. Commissioned paper for Independent International Commission on Health Research for Development. Boston: Harvard School of Public Health (n/d).

TANNER, M. (1989). Evaluation and monitoring of schistosomiasis control. Tropical Medicine and Parasitology 40 (in the Press).

TANNER, M. \& DEGRÉMONT, A. (1986). Monitoring and evaluating schistosomiasis control within a primary health care programme. Tropical Medicine and Parasitology 37, 220-2.

TANNER, M. \& DE SAVIGNY, D. (1987). Monitoring of 
community health status: experience from a case study in Tanzania. Acta Tropica 44, 261-70.

TANNER, M., LWIHULA, G. K., BURNIER, E., DE SAVIGNY, D. \& DEgRÉMONT, A. A. (1986). Community participation within a primary health care programme. Tropical Medicine and Parasitology 37, 164-7.

TANNER, M., DEGRÉMONT, A., DE SAVIGNY, D., FREYVOGEL, T. A., MAYOMBANA, C. \& TAYARI, S. (1987a).

Longitudinal study on the health status of children in Kikwawila village, Tanzania: study area and study design. Acta Tropica 44, 119-36.

TANNER, M., BURNiER, E., MAYOMBANA, C., BETSCHART, B., DE SAVIGNY, D., MARTI, H. P., SUTER, R., AEllen, M., LUEDIN, E. \& DEGRÉMONT, A. A. (1987b). Longitudinal study on the health status of children in a rural Tanzanian community: parasitoses and nutrition following control measures against intestinal parasites. Acta Tropica 44, 137-74.

TANNER, M., DE SaVignY, D., Mayombana, C., hatz, C., BURNIER, E., TAYARI, S. \& DEGRÉMONT, A. A. (1989). Morbidity and mortality at Kilombero; a districtbased research-cum-action programme. Working paper for consultation on disease and mortality in sub-Saharan Africa: levels, trends and data deficiencies. Tunbridge Wells 1987. Washington: World Bank (in the Press).

vaughan, P., Mills, A. \& SMITh, D. (1984). District health planning and management. EPC Publication No. 2. London: Evaluation and Planning Center, London School of Hygiene and Tropical Medicine.
WALSh, J. \& WARREN, K: S. (1986). Strategies for Primary Health Care. Chicago: University of Chicago Press. WATT, J. M. \& BREYER-BRANDWIJK, M. G. (1962). The Medical and Poisonous Plants of Southern and Eastern Africa. Edinburgh: E. \& S. Livingstone.

WERNER, D. (1980). Health care and human dignity - a subjective look at community-based rural health programmes in Latin America. Contact Special Series No. 3. Geneva: CMC and WCC.

WORLD HEALTH ORGANIZATION (1978). Declaration of Alma Ata (report on the international conference on primary health care, Alma Ata, USSR, 6-12 September 1978). Geneva: WHO Publications. WORLD HEALTH ORGANIZATION (1982). Review of primary health care development. WHO Offset Publication SHS/82.3. Geneva: WHO Publications.

WORLD health organization (1983). Mimimum evaluation procedures for water supply and sanitation projects. WHO Publication ETS/83.1 and CDD/ORP/83.1. Geneva: WHO Publications. WORLD HEALTH ORGANIZATION (1984). Strengthening ministries of health for primary health care. Offset Publication 82. Geneva: WHO Publications.

WORLD HEALTH ORGANIZATION (1987). Declaration on strengthening district health systems based on primary health care. Geneva: WHO Publications. WORLD HEALTh ORGanization (1988). From Alma-Ata to the year 2000: a midpoint perspective. Riga: WHO documents $(\mathrm{n} / \mathrm{d})$. 